\title{
Integration of Pharmacy Education and Pharmacovigilance: Scope and Challenges in India
}

\author{
Reddy Vobbineni Lokesh*, Adusumilli Pramod K, Bhushan Shashi, Vivekandan Kalaiselvan, \\ Singh Gyanendra Nath
}

Department of Training and Education, National Co-ordination Centre- Pharmcovigilance Programme of India, Indian Pharmacopoeia Commission, Sector 23, Rajnagar, Ghaziababd, Uttar Pradesh- 201002, INDIA.

\begin{abstract}
Aim: Pharmacy Council of India (PCI) and the All India Council for Technical Education (AICTE) are the two professional organizations which are presently regulating the pharmacy education in India. Curriculum change of pharmacy education has been undertaken by central government notification as per amendment of pharmacy act. Methods: All the information and data has been obtained from standard articles, books and official websites including current scenario and topics. Results: Introduction of Pharm. D program concerning the significance of Pharmacy Practice and clinical exposure for students is a remarkable step taken by $\mathrm{PCl}$ in the year 2008. Pharmacovigilance (PV) is the science, which maintains the safety and rational therapy, making an essential checkpoint for regulatory utilization and movement of drugs and medicines is main component of pharmacy practice. However, in spite of all the achievements regarding the significance of $\mathrm{PV}$ and its efforts, awareness and knowledge about rational utilization of drugs and its side effects is low. However, an aspect common to all developing countries, despite of economic level is that the PV education in universities is far below the minimum requirements to sustain an effective drug monitoring system. Conclusion: As future prospects increase, PV systems capable to detect new ADRs and taking regulatory actions are needed to protect public health which will achieved only by further strengthening the existence system and enhancing the quality of PV education.
\end{abstract}

Key words: Pharmacovigilance, Pharmacy education, Awareness, Students Empowerment, Pharm. D, Career opportunities.

Key messages: Awareness and knowledge about rational utilization of drugs and its side effects is must. It can be achieved by integration of Pharmacovigilance as course in Pharmacy education in India. In educational institutions, well qualified faculty with significant knowledge and skills in PV is required.

\section{INTRODUCTION}

India, being second most populous country in the world and a developing country with a great biodiversity, has been achieving a rapid growth in fields of science and technology. Academically considering $19^{\text {th }}$ century situations, Pharmacy curriculum was mainly focused on Pharmaceutical Chemistry, analytical chemistry rather than Pharmacy practice, which provided opportunities for graduates to work in pharmaceutical companies as specialists in Quality Control and Standardization of Drugs. ${ }^{1}$ After rapid industrialization and economic growth in late 1980's, there is a leap in growth of pharmacy education at higher rate than any other countries in the world. ${ }^{2}$ In current scenario, worldwide movement in improving patient safety is at pace, besides drug safety and monitoring becomes even more important. ${ }^{3}$ Pharmacovigilance (PV), a branch of pharmaceutical sciences has significant impact on public health safety and improving
Submission Date: 05-04-2018; Revision Date: 30-10-2018; Accepted Date: 12-12-2018

DOI: 10.5530/ijper.53.2.26 Correspondence:

Dr. Vobbineni Lokesh Reddy,

Department of Training and Education, National Coordination Centre- Pharmcovigilance Programme of India, Indian Pharmacopoeia Commission,

Sector 23, Rajnagar, Ghaziababd, Uttar Pradesh201002, INDIA.

Phone: +91-9581931546 E-mail: loku25.reddy@gmail. com

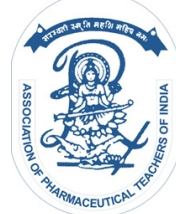

www.ijper.org 
quality of life parameters by detecting, assessing, reporting and understanding of Adverse Drug Reactions (ADRs). ${ }^{4} \mathrm{PV}$ insists for the safety and rational therapy, making an essential checkpoint for regulatory utilization and movement of drugs and medicines in most of the countries.

Many countries regulating PV program under their respective Government national regulatory authorities unified by international World Health Organization (WHO), Uppsala Monitoring Centre, located in Sweden. The discipline of PV has developed considerably since the 1972 WHO technical report and it remains a dynamic clinical and scientific discipline. It has been essential to meet the challenges of the increasing range and potency of pharmaceutical medicines, which carry with them an inevitable and sometimes unpredictable potential for harm in term of ADR. The risk of ADR, however, is less when medicines are used by an informed health profession and by patients, who themselves understand and share responsibility for their drugs. ${ }^{5-6}$

Under the Aegis of Ministry of Health and Welfare, PV activities are regulated by National Coordination Centre (NCC) for Pharmacovigilance Programme of India (PvPI), located at Indian Pharmacopoeia Commission (IPC), Ghaziabad, Uttar Pradesh, India. PvPI besides its immense growth in recent decade turned from a mere public health program service to an esteemed organisation with 250 ADR monitoring centres, which were spread all over India to ensure the patient safety. It has also taken its adventurous milestone as WHO collaborating centre for PV in public health programs and regulatory activities. Its Collaboration with various national health programmes such as National vector Borne Disease control Programme (NVBDCP), National AIDS control Organisation (NACO), National Deworming Day (NDD), adverse events Following Immunisation (AEFI) and Revised National Tuberculosis Control Programme (RNTCP) has been a noteworthy evolution of its concern towards public health safety. Yet another notable progress for its consistent and reliable performance in Signal detection is also achieved by providing regular recommendations to drug regulatory body Central Drugs Standard Control Organization (CDSCO) on different drug safety issues, which is later disseminated to all stakeholders of IPC and it has been made as a legal obligation for pharmaceutical industries to report ADRs to PvPI and to submit Periodic Safety Update Report (PSUR) to the National Regulatory Authority i.e., CDSCO as per the amendment in schedule Y of Drugs and Cosmetics Act of 1945.7

Pharmacy Council of India (PCI) and the All India Council for Technical Education (AICTE) are the two professional organizations which presently regulating the Pharmacy education in India. ${ }^{8-9}$ AICTE approved colleges for bachelor degree in pharmacy as regional wise across India was shown in Figure 1a, whereas number of PCI approved pharmacy colleges which offering various pharmacy courses in India was presented in Figure 1b. Curriculum change of pharmacy education has been undertaken by central government notification as per amendment of pharmacy act. Recently in 2016, bachelor degree has been revised and regularised uniformly all over India for all Institutions. Introduction of six years Pharm.D and three years' post baccalaureate programs concerning the significance of Pharmacy Practice and clinical exposure for students are remarkable steps taken by PCI in 2008 .

However, In spite of all the achievements so far to have credibility of impact on nation like India regarding the significance of PV and its efforts, awareness and knowledge about rational utilization of drugs and its side effects is must. It can be achieved by integration of PV as course in Pharmacy education in India. This can improve clinical knowledge and skills of PV activities among future pharmacists.

\section{SCOPE OF PV CURRICULUM}

Teaching of PV in Universities is one of those essential activities that are required, if we are to move forward with the objective of detection, evaluation and prevention of ADRs of medicines on patients and on population. Reporting arises from the perception of healthcare professionals, which in turn depends on the working environment and abilities of individuals as well as the PV system present. It appears clear that the teaching of PV can be focussed on several aspects and with different levels of complexity and completeness in the PV content. ${ }^{10-11}$

\section{A. Role of Regulatory bodies in promoting PV importance in India}

The fundamental issue concerns, whether the teaching sufficiently produces the expertise in PV, so that the pharmacists can perform the PV activities and contribute to the system. Considering the context, introduction of PV as one of the subjects in revised syllabus of pharmacy under graduation course in $8^{\text {th }}$ semester by PCI in India is a key progress that will provide an opportunity to students in understanding basic terminologies, current scenario and various methods to generate safety data and signal detection. ${ }^{12}$ Besides which other regulatory authorities have contributed their prominent role in improvising and promoting successful PV activities at international level by collaborating with esteemed 


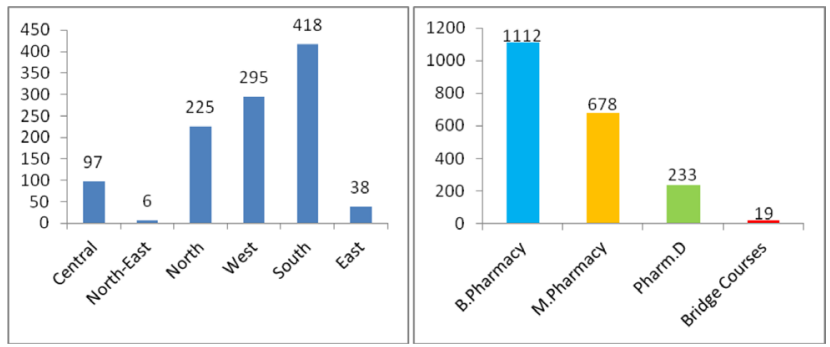

Figure 1a: Regional Wise AICTE approved Pharmacy (degree) colleges in India.

Figure 1b: $\mathrm{PCl}$ approved Pharmacy Colleges offering various Courses in India.

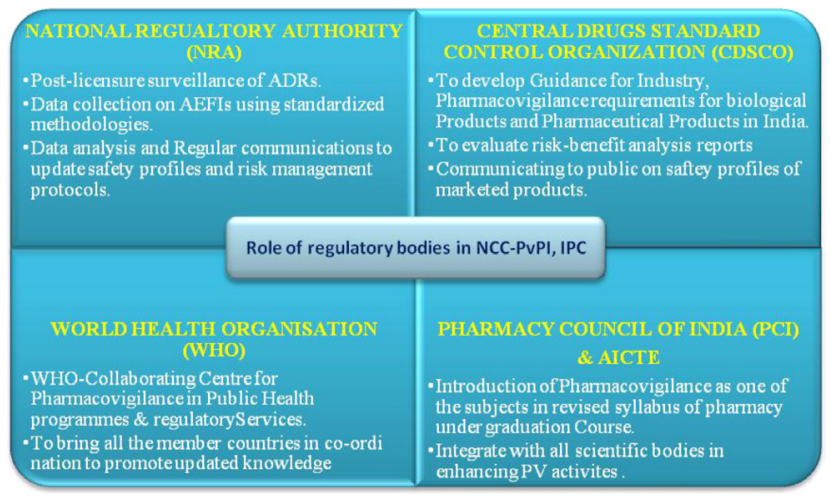

Figure 2: Role of regulatory authorities in promoting PV through NCC-PvPI, IPC in India.

representative (NCC- PvPI) for PV in India. The respective roles of regulatory bodies are shown in Figure 2.

\section{B. Employment opportunities in PV}

In India, currently PV is emerging as a powerful career perspective in both private and government sectors. For most of the Pharmacy students PV has been providing vast opportunities not only in India but also in abroad and it is the responsibility of educational institutions to provide enough practical exposure so that they can develop decision making skills which in turn provide through well trained PV professionals at their educational level. Many corporate industries are providing massive career placements in PV platform. Besides, PvPI has also been offering good career opportunity to young and talented pharmacy professionals to represent as patient safety associates in AMCs (ADR Monitoring Centres) all over India. A brief flow chart review of career opportunities in PV has been provided in Figure 3.

To meet the needs of scientific approach in dispensing and optimisation of rational therapy requires knowledge of evidence based drug therapy. Therapeutic agents with novel mechanism of actions are increasingly available and understanding of benefit/risk ratio profiles and

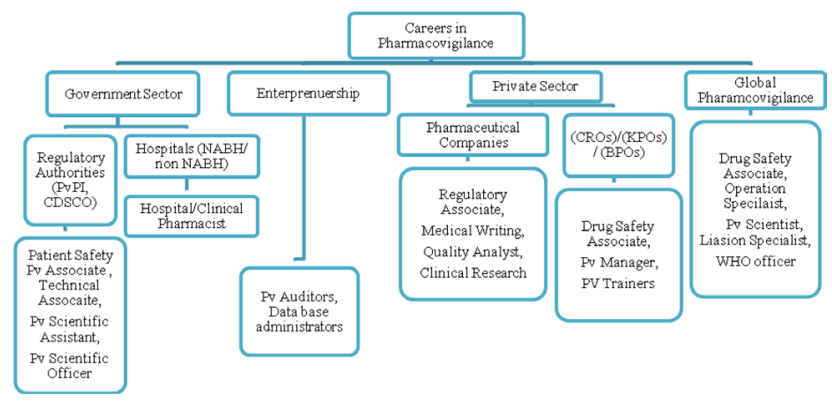

Figure 3: Representation of different PV career options in India after Pharmacy graduation.

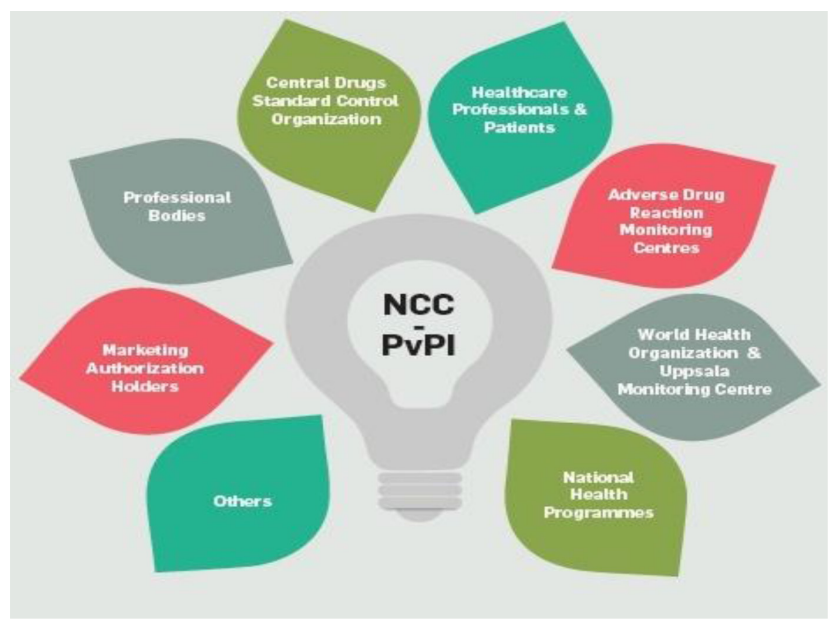

Figure 4: Professional relationship of NCC-PvPI with PV stakeholders.

safety concerns is very important. Hence in educational institutions, well qualified faculty with significant knowledge and skills in PV is required. ${ }^{11}$

\section{Collaboration of PV with various stakeholders}

An intricate relationship exists between wide ranges of partners in the practice of drug safety monitoring such as government, industry, health care centres, hospitals, academia, medical and pharmaceutical associations, poisons information centres, health professionals, patients, consumers and media. Persistent collaboration and dedication are vital, if future challenges in PV are to be met in order to expand and prosper. ${ }^{6}$ In this context, NCC-PvPI has been working closely with various PV stakeholders in building a strong networking and professional relationship. The details of various PV stakeholders are provided in Figure 4.

Pharmacy education and career has multi-disciplinary approach in industries, hospitals, health care regulatory bodies and community practice. Hence, students with such prospectus must have exposure and keen understanding of system and network flow, besides their 
collaboration in improving rational use of drugs and promoting better health care of patients.

\section{Role of PvPI in PV skill development and training}

The PvPI has major responsibility of improving awareness and providing continuing education services to students, academicians, industrialists, regulatory officials, health care professionals and consumers. Recent implementation of periodical training programme since 2016 by PvPI has been proven to be a successful step for awareness and emphasizing the significance of PV among participating delegates. The positive and overwhelming response shown by young Undergraduate and Postgraduate students shows the interest of their learning and enthusiasm towards $\mathrm{PV} .^{13}$

In India, 250 AMCs are available in all states, which are approachable to almost all pharmacy institutions. In order to have a practical perception of systemic workflow of PvPI, educational institutions should have collaboration with nearest possible AMCs and should encourage students to have good and regular communication with respective AMC PV associates. Students will have a good opportunity to improve their quality of reporting, to keep up updates on new signals and contributing to the PV system.

Hence, establishing the strong PV curricula in India may help in major expected outcomes prioritized through these training sessions on creating a workforce at national/international level to meet challenges in PV and providing trained PV professionals, who are well versed with Good Pharmacovigilance Practices (GVP).

\section{CHALLENGES}

PV activities and its performance vary from country to country. Drug's availability and quality are not same in all countries due to economic, regulatory and technological differences. Similarly, populations of different countries vary based on their environmental, health and literacy conditions. Health priorities, policies and epidemiological factors vary among continents, countries and regions. Thus, when planning PV integration in educational program, it is important to identify PV priorities for each country and for each region. ${ }^{6}$

\section{A. Empowerment for PV in Pharmacy Profession}

Since 2008, PV and management of ADRs have been confined to as a topic in Clinical Pharmacy subject for fourth year students of Pharm.D course. Though there is practical exposure for students to get trained, assess and understand the significance of reporting ADRs in most of the institutions, ADR reporting is considered as one of health care responsibilities for those students, who are under clerkship and internship activity as it has been related to criteria for fulfilment of their respective course curriculum only. This attitude and perception has to be exempted and should be considered as a responsibility for all pharmacy students.

The thought of students should be asserted that, whether new or old drugs, their incidence of adverse events are frequent and practice of ADR reporting should be adopted as a continual responsibility, throughout their practice in health care. This requires educational intervention at their under-graduation level for which integration of PV course in all branches of health sciences is necessary. Though several interventions have proven effective for practising PV by health care professionals and students, which are theoretical (lectures) rather than active forms of learning (practical/ hands on training). Some studies have proven that practice based method led to more and better qualitative ADR reports and such exposure and practice will be necessary to master clinical skills. ${ }^{14}$

\section{B. Lack of Knowledge and Skills about PV among HCPs}

Knowledge on medications by a pharmacist should be updated on regular basis and has to keep in pace with current trends and regulations regarding the newly introduced medication approvals, recalls, cautions and PSURs. Lack of effective communication skills has been a major barrier to sensitize health care professionals and community regarding significance of ADR reporting and awareness. This can be minimized by Proper utilization of presentations, aiding materials, pamphlets and evidence based outcomes. PvPI has been contributing its dynamic role in this issue by conducting continuous professional education, which can be effectively utilized by all health care professionals, students, employees in all over India.

The challenge of maximizing drug safety and maintaining public confidence has become increasingly complex. ${ }^{15}$ The biggest challenge facing the PV in India is the gross under reporting of adverse effects from all public. There are many reasons for this, including lack of medical expertise in drug administration and adequate skilled resources in PV and inadequate nationwide awareness of PV. Hence, bringing up the PV syllabus in UG programme will help in creating the basic awareness about the need for reporting ADRs.

\section{Comparison of PV working system with abroad}

Unlike foreign countries, who have well organised collaboration of PV-National Co-ordinating Centres 
with their educational institutions, India has to achieve through sustained integration with institutions. This can attain an exponential change in health care professionals and even in patient's attitude towards ADR reporting. For an instance in Netherlands and Sweden, year by year there is a constant increasing rate of spontaneous ADR reports from consumers and have significant contribution $(19.3 \%)$ by them and also data provided by consumers was utilised for identification of signal detection, ${ }^{16}$ whereas in India contribution from consumers is minimum $(5.34 \%)$ as per the data obtained from NCC-PvPI.

\section{Need for effective role of PV professionals (Clinical Pharmacists) in Hospitals}

Sometimes, ADRs are not recognized by the physicians on patient's hospitalization and that may be responsible for the death of those patients. At this moment, Clinical pharmacists play a crucial role in identification and management of some of the serious adverse events in consultation with physician. They have to lead the activities of ADR management and reporting, prescription event monitoring, medication error minimization, continuous medical education.

Pharmacy students should be encouraged in participating health awareness camps in association with other medical and para-medical professional students in community settings. Furthermore, the financial cost of ADRs to the healthcare system is also vast. This can be minimised by active involvement of pharmacist in early detection and reducing the economic burden to patient from hospitalization due to ADRs which can be attained only, if the pharmacist have enough practical exposure in PV. ${ }^{17}$

\section{E. Need for Initiative Steps by All State Governments in Awareness for PV}

Safe and rational use of drug at rural levels is always a challenge in India. There are few statistics and reports are available regarding rational use of medicines and optimal therapy practice in rural and district regions of Country. Suspected Unexpected Serious Adverse Reactions (SUSAR) has high impact on quality of treatment and compliance towards therapy. Hence it is important that these should be analysed and communicated effectively to all health care professionals. It is the prime responsibility of PV, which will be achieved through integration of the discipline into public policy and medical practice. ${ }^{18}$ State Government authorities should take initiatives in effective implementation of PV awareness Programmes into district, regional and rural levels. In the market, when new medicines are launched without long term safety studies, patients experiencing ADRs will be at high stake, hence pharmacists has, to sense the significance of reporting of ADRs of new marketed drugs to PV system in the country, which finally leads to decision making of rational use by drug regulators. However, State Health Regulatory authorities are recommended to regularise PV in all Government Hospitals. This can persuade students and health care professionals to be passionate about PV as a promising career.

\section{CONCLUSION}

The proper implementation of PV in academics, both in UG and PG curricula are very important. The teaching of PV in Pharmacy colleges is necessary because clinical expertise plays a crucial role in the discovery of druginduced diseases, signal generation and assessment. PV contributes to the knowledge about how and when ADR occur and about the national and international reporting systems. However, an element common to many countries, despite of economic level or development of PV system, is that the PV teaching in Universities is far below the minimum requirements to help sustain an effective post marketing drug monitoring system dependent on pharmacists as active participants.

As future prospects increase, PV systems capable to detect new ADRs and taking regulatory actions are needed to protect public health. Little emphasis has been put into generating information that can assist a healthcare professional or a patient in the decision-making process. The gathering and communication of this information is an important goal of PV.

\section{CONFLICT OF INTEREST}

The authors declare no conflict of interest.

\section{ABBREVIATIONS}

PCI: Pharmacy Council of India; AICTE: All India Council for Technical Education; PV: Pharmacovigilance; ADRs: Adverse drug reactions; WHO: World Health Organization; NCC: National Coordination Centre; PvPI: Pharmacovigilance Programme of India; IPC: Indian Pharmacopoeia Commission; NVBDCP: National vector Borne Disease control Programme; NACO: National AIDS control Organisation; NDD: National Deworming Day; AEFI: Adverse Events Following Immunisation; RNTCP: Revised National Tuberculosis Control Programme; CDSCO: Central Drugs Standard Control Organization; PSUR: Periodic Safety Update Report; GVP: Good Pharmacovigilance Practices; SUSAR: Suspected Unexpected Serious Adverse Reactions. 


\section{REFERENCES}

1. Singh H. History of pharmacy in India and related aspects. Vallabh Prakashan. 1994

2. Sachan A, Sachan AK, Gangwar SS. Pharmacy education in India and its neighbouring countries. International Current Pharmaceutical Journal. 2012;1(9):294-301.

3. Olsson S. Pharmacovigilance training with focus on India. Indian Journal of Pharmacology. 2008;40(Suppl 1):S28.

4. Biswas P. Pharmacovigilance in Asia. Journal of Pharmacology and Pharmacotherapeutics. 2013;4(Suppl 1):S7.

5. Huang YL, Moon J, Segal JB. A comparison of active adverse event surveillance systems worldwide. Drug Safety. 2014;37(8):581-96.

6. Suke SG, Kosta P, Negi H. Role of pharmacovigilance in India: An overview. Online Journal of Public Health Informatics. 2015;7(2).

7. Central Drugs Standard Control Organization [homepage on the Internet]. New Delhi: Pharmacovigilance Programme of India. [updated 2014 Aug 24; cited 2018 Feb 21]. Available from: http://www.cdsco.nic.in/forms/ contentpage1 .aspx?lid=1752.

8. Pharmacy Council of India [homepage on the Internet]. New Delhi: c2010 [cited 2017 December 18]. Available from: http://www.pci.nic.in/.

9. All India Council for Technical Education [homepage on the Internet]. List of AICTE approved Institutes in Pharmacy 'UG' for the state Andhra Pradesh for the academic year: 2017-2018 [cited: 2018 Feb 21]. Available from: https://www.facilities.aicte-india.org/dashboard/pages/angulardashboard. php\#!/approved.
10. Alldredge BK, Koda-Kimble MA. Count and be counted: preparing future pharmacists to promote a culture of safety. American Journal of Pharmaceutical Education. 2006;70(4):92.

11. Comoglio RH, Alesso L. Teaching Pharmacovigilance in University. In Pharmacovigilance 2017;1-8.

12. Pharmacy Council of India [database on the Internet]. New Delhi: The Revised Regulations for the B. Pharm. Degree. Program (CBCS) of the Pharmacy Council of India. c2010. [cited: 2018 Feb 21]. Available from: http:// pci.nic.in/CollegesCourses/RevisedNewSyllabus.pdf.

13. National coordination centre- Pharmacovigilance programme of India, editor. 5th skill development programme on Basics and regulatory aspects of PV. Newsletter. 2017;7(20):13.

14. Schutte T, Tichelaar J, Reumerman MO, Eekeren VR, Rolfes L, Puijenbroek VEP, et al. Feasibility and educational value of a student-run pharmacovigilance programme: a prospective cohort study. Drug Safety. 2017;40(5):409-18.

15. World Health Organization. The safety of medicines in public health programmes: pharmacovigilance, an essential tool.

16. Härmark L, Hunsel VF, Grundmark B. ADR reporting by the general public: lessons learnt from the Dutch and Swedish systems. Drug Safety. 2015;38(4):337-47.

17. Mann RD, Andrews EB. Editors Pharmacovigilance. John Wiley and Sons. 2007.

18. Moore $\mathrm{N}$. The role of the clinical pharmacologist in the management of adverse drug reactions. Drug Safety. 2001;24(1):1-7.

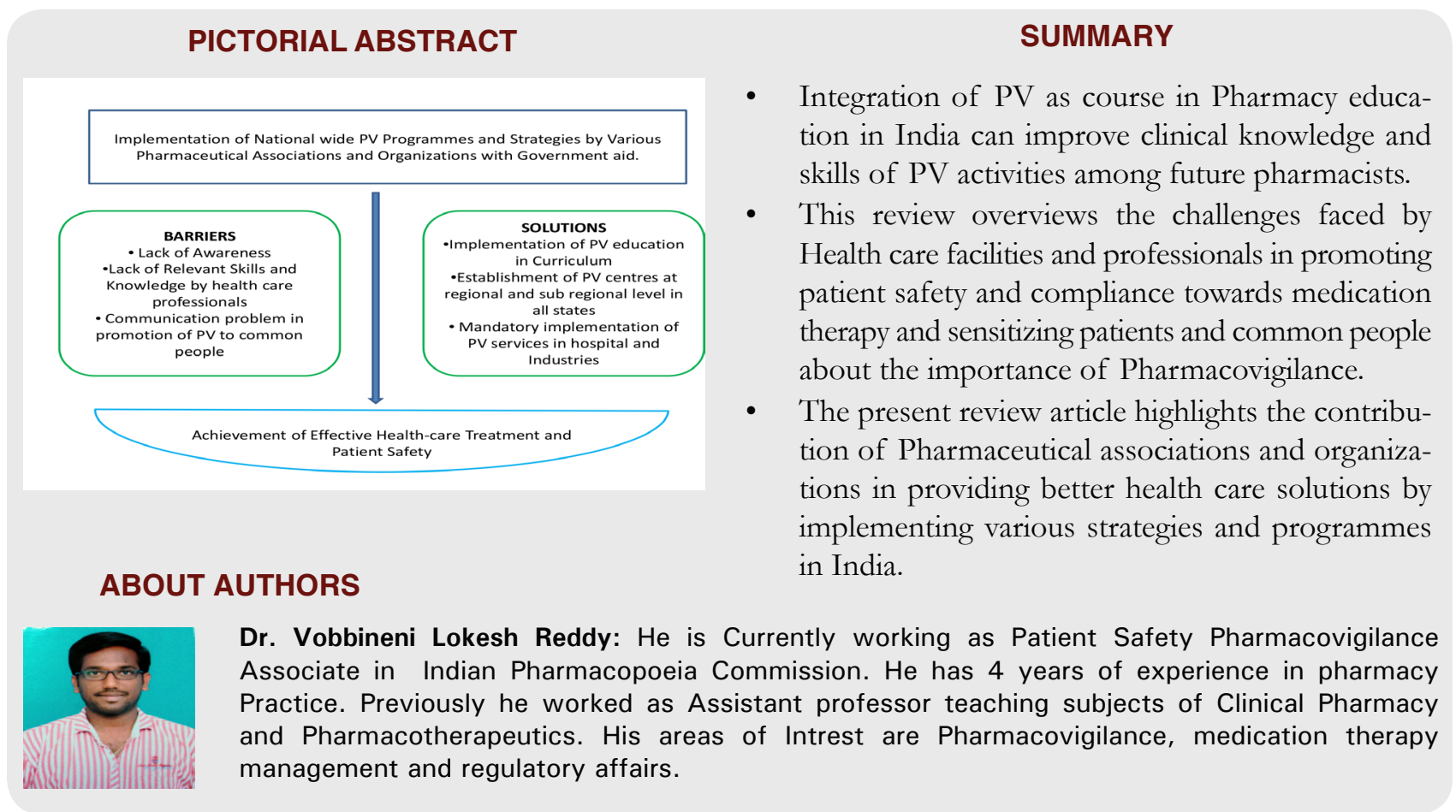

Cite this article: Lokesh RV, Pramod AK, Shashi B, Kalaiselvan V, Nath SG. Integration of Pharmacy Education and Pharmacovigilance: Scope and Challenges in India. Indian J of Pharmaceutical Education and Research. $2019 ; 53(2): 202-7$. 